\title{
Increased incidence of glucose disorders during pregnancy is not explained by pre-pregnancy obesity in London, Canada
}

\author{
Margie H Davenport ${ }^{1}$, M Karen Campbell ${ }^{2,3,4,5}$, Michelle F Mottola ${ }^{1,5,6^{*}}$
}

\begin{abstract}
Background: The increasing incidence of impaired glucose tolerance (IGT), gestational diabetes (GDM) and type 2 diabetes (T2D) during pregnancy was hypothesized to be associated with increases in pre-pregnancy body mass index (BMI). The aims were to 1) determine the prevalence of IGT/GDM/T2 D over a 10 year period; 2 ) examine the relationship between maternal overweight/obesity and IGT/GDM/T2D; and 3) examine the extent to which maternal metabolic complications impact maternal and fetal pregnancy outcomes.

Methods: Data arose from a perinatal database which contains maternal characteristics and perinatal outcome for all singleton infants born in London, Canada between January 1, 2000 and December 31, 2009. Univariable and multivariable odds ratios (OR) were estimated using logistic regression with IGT/GDM/T2 D being the outcome of interest.

Results: A total of 36,597 women were included in the analyses. Population incidence of IGT, GDM and T2 D rose from $0.7 \%, 2.9 \%$ and $0.5 \%$ in 2000 to $1.2 \%, 4.2 \%$ and $0.9 \%$ in 2009. The univariable OR for IGT, GDM and T2 D were $1.65,1.52$ and 2.06, respectively, over the ten year period. After controlling for maternal age, parity and prepregnancy BMI the OR did not decrease. Although there was a positive relationship between pre-pregnancy BMI and prevalence of IGT/GDM/T2 D, this did not explain the time trends in the latter. Diagnosis of IGT/GDM/T2 D increased the risk of having an Apgar score $<7$ at 5 minutes, which was partially explained by gestational hypertension, high placental ratio, gestational age and large for gestational age babies.
\end{abstract}

Conclusions: We found a significant increase in the incidence of IGT/GDM/T2 D for the decade between 20002009 which was not explained by rising prevalence of maternal overweight/obesity.

\section{Background}

Maternal glucose disorders (MGD) during pregnancy include gestational diabetes mellitus (GDM), impaired glucose intolerance (IGT) and pre-pregnancy type 2 diabetes. GDM is defined as glucose intolerance with onset or first diagnosis during pregnancy $[1,2]$. This is a common disease affecting 3-4\% of pregnancies in Canada [1]. Recent data from the United States and Australia have indicated that the prevalence of GDM is on the rise. However, the underlying cause is unknown [3-12]. Postulated mechanisms include the concomitant rise in

\footnotetext{
* Correspondence: mmottola@uwo.ca

${ }^{1}$ R. Samuel McLaughlin Foundation Exercise and Pregnancy Lab, School of Kinesiology, The University of Western Ontario, London, Ontario, N6A 3K7, Canada

Full list of author information is available at the end of the article
}

obesity $[12,13]$ and decrease in physical activity $[14,15]$. In 2000, 30\% of American adults were obese (body mass index (BMI) $\geq 30 \mathrm{~kg} / \mathrm{m}^{2}$ ) representing a $23 \%$ increase over the previous decade [16]. In a study of nine US states, the prevalence of maternal obesity increased 69.3\% from 1993-2003 [17]. Several studies have demonstrated that MGD is strongly related to maternal obesity $[18,19]$. However, none of the studies previously examining the time trend of MGD had pre-pregnancy BMI available in their database [3-11]. Therefore, ours is the first to examine the relationship between pre-pregnancy BMI and changes in the prevalence of MGD.

The objectives of the present study were: 1 ) to describe the annual prevalence of MGD (including GDM, type 2 diabetes and IGT) over a 10 year period; 2) to examine the relationship between annual prevalence of maternal

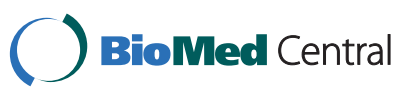


overweight/obesity and MDG prevalence to determine the extent to which they are associated; and 3) to examine, at the individual level, the extent to which maternal metabolic complications impact on maternal and fetal pregnancy outcomes. We hypothesized that, between 2000-2009, the prevalence of maternal glucose disorders will have increased, especially in women with a BMI $\geq 25$ $\mathrm{kg} / \mathrm{m}^{2}$. It was also hypothesized that the time trend of maternal glucose disorders would be explained by the time trend of overweight/obesity. Finally, we hypothesized that the offspring of pregnancies affected by maternal glucose disorders would have an increased incidence of pregnancy complications compared with the normal obstetrical population.

\section{Methods}

The following protocol has been approved by the Research Ethics Board for the Review of Health Sciences Research Involving Human Subjects at the University of Western Ontario. We conducted a retrospective cohort study using data from the Saint Joseph's Health Care Perinatal Database which contains data from medical records, including delivery and neonatal information. Data from all births occurring in London, Canada are prospectively collected and entered into this large perinatal database by a dedicated research assistant. The study population was selected based on the following criteria: delivery between January 1, 2000 and December 31, $2009(\mathrm{n}=36,597)$, singleton pregnancy and residence in London, Canada. Women diagnosed with type 1 diabetes prior to pregnancy were removed from the dataset. The following data were used for analyses: maternal characteristics (age, parity, height (measured during prenatal visit), pre-pregnancy weight (from maternal recall), excessive weight gain, previous GDM or pre-existing type 2 diabetes, pre-existing hypertension, gestational hypertension (including pregnancy induced hypertension and pre-eclampsia), IGT and diagnosis of GDM - which may include previously undiagnosed type 2 diabetes), infant characteristics (gestational age, birth and placental weight) and pregnancy outcomes (type of delivery and Apgar scores). After the data were checked for errors, all identification (including names and hospital record numbers) was stripped to ensure anonymity of the data. Large for gestational age (LGA) and small for gestational age (SGA) were identified using Canadian birth weight for gestation distributions [20]. A ratio dividing placental weight (g) by infant birth weight (g) was determined. Maternal pre-pregnancy weight and height were taken from medical records. Maternal pre-pregnancy BMI was calculated using pre-pregnancy weight $(\mathrm{kg}) /[\text { height }(\mathrm{m})]^{2}$. Excessive pregnancy weight gain was defined as weight gain from pre-pregnancy weight to delivery weight $\geq 20 \mathrm{~kg}$ in the database. Type 2 diabetes, GDM and IGT were taken directly from diagnosis entered into the database. All pregnant women in Canada are screened and diagnosed for these diseases according to guidelines set by the Canadian Diabetes Association [1,2].

All analyses were performed using the Statistical Analysis System 9.1.3 (SAS Institute, Cary, NC) and Statistical Package for the Social Sciences, version 16 (SPSS Inc, Chicago, Ill). The annual prevalence of maternal glucose disorders from 2000-2009 (Objective 1) within strata (by year, body mass index (BMI), age and/or parity) was estimated as a proportion and standard error of the estimate. To address Objective 2, prevalence of maternal glucose disorders by pre-pregnancy BMI categories (underweight $\left(<18.5 \mathrm{~kg} / \mathrm{m}^{2}\right)$, normal weight $\left(18.5-24.9 \mathrm{~kg} / \mathrm{m}^{2}\right)$, overweight $\left(25-29.9 \mathrm{~kg} / \mathrm{m}^{2}\right)$ and Class I, II and III obese $\left(30-34.9 \mathrm{~kg} / \mathrm{m}^{2}, 35-39.9 \mathrm{~kg} / \mathrm{m}^{2}\right.$ and $\geq 40 \mathrm{~kg} / \mathrm{m}^{2}$, respectively) were summarized using frequency distributions. Repeated measures ANOVA was used to determine the increase in overweight/obesity over time. $\mathrm{P}<0.05$ indicates statistical significance. Univariable and multivariable odds ratios were estimated using logistic regression with the outcome of interest being MGD (IGT, GDM and type 2 diabetes). Predictive factors were entered in a blockwise fashion in order to allow for a careful examination of the relative contributions of each predictive factor to the relationship between year and MGDs. Year, maternal age and parity were entered in the first block, BMI in the second block and excessive weight gain in the third block. To address objective 3 , frequency distributions and mean \pm SD of 1) IGT; 2) GDM; 3) type 2 diabetes; and 3) no metabolic disorder were created. Univariable and multivariable odds ratios were estimated using logistic regression with the outcome of interest being Apgar $<7$ at 5 minutes after birth. Apgar $<7$ at 5 minutes after birth was chosen as a proxy for neonatal well-being, because a variety of clinical events that affect the well-being of the infant will be reflected in the Apgar score [21].

\section{Results}

We examined data from 36,597 women who gave birth between Jan 1, 2000 and Dec 31, 2009 in London, Ontario, Canada. Description of the sample follows with mean \pm standard deviation (min-max). The women were $29.5 \pm$ 5.5 (14.1-47.9) years old, $165 \pm 10$ (103-195) cm tall, with a pre-pregnancy body mass of $67.0 \pm 15.9(31.8-189.6) \mathrm{kg}$ and a pre-pregnancy BMI of $24.7 \pm 5.5(14.6-67.5) \mathrm{kg} / \mathrm{m}^{2}$. Pre-pregnancy BMI was unavailable for 8,611 women. These women were not included in the analysis.

Incidence of maternal glucose disorders from 2000-2009 Pregnancies affected by type 2 diabetes increased significantly from $0.5 \%$ in 2000 to $0.9 \%$ in 2009 ( $p=0.001$ ). 
The prevalence of GDM significantly increased over the same period from $2.9 \%$ to $4.2 \%(\mathrm{p}=0.002)$ and the prevalence of IGT increased from $0.7 \%$ to $1.2 \%(\mathrm{p}=0.001)$.

The prevalence of pre-pregnancy overweight and obesity did not significantly change between 2000 and 2009 and were, respectively, $22.1 \%$ and $14.4 \%$ in 2000 and $22.2 \%$ and $16.0 \%$ in 2009 . The p-values attached to changes in prevalence were $\mathrm{p}=0.79$ for overweight and $\mathrm{p}=0.43$ for obesity. Thus, there was not an association with the time trend in MGT. However, ignoring time trends, there was a positive relationship between BMI and maternal glucose disorders in that as BMI category increased, the prevalence of maternal glucose disorders also increased (Table 1).

Univariable and multivariable associations of year, maternal age, parity, BMI and excessive weight gain with MGDs are presented in Table 2. Univariable analyses indicate a $65 \%, 52 \%$ and $206 \%$ increase in the prevalence of IGT (OR: 1.65, 95\% CI: 1.12 - 2.43), GDM (OR: 1.52, 95\% CI: 1.25-1.83)) and type 2 diabetes (OR: 2.06, 95\% CI: $1.29-3.27$ ), respectively, for the decade between 2000 and 2009 with a slight amplification of these ORs after control for covariates. Therefore, the increase in the prevalence of maternal glucose disorders over time was not explained by BMI nor was it explained by excessive pregnancy weight gain (IGT aOR: 2.09, 95\% CI: 1.36-3.20; GDM aOR: 1.68, 95\% CI: $1.35-$ 2.10; type 2 diabetes aOR 2.33, 95\% CI: 1.38 -3.92) (Table 2). Strong univariable and multivariable associations were demonstrated between BMI and MGDs.

\section{Maternal glucose disorders and pregnancy outcome} Diagnosis of IGT or GDM during pregnancy was associated with an increased incidence of of LGA, caesarean section delivery and gestational hypertension (Table 3) whereas diagnosis of type 2 diabetes during pregnancy was associated with increased frequency of LGA, Apgar $<7$ at 5 minutes, caesarean section delivery and gestational hypertension. The incidence of SGA is slightly lower. Univariable analysis indicates that the risk of having an Apgar $<7$ at 5 minutes after delivery is higher in IGT (OR 1.87, 95\% CI: 1.36 - 2.56), GDM (OR 1.50, 95\% CI: 1.27 - 1.77), type 2 diabetes (OR 2.99, 95\% CI: 2.17 - 4.12), BMI $\geq 30 \mathrm{~kg} / \mathrm{m}^{2}$ (OR 1.54, 95\% CI: 1.38 - 1.71), high placental ratio (OR
1.93, 95\% CI: 1.76 - 2.12) and gestational hypertension (OR 1.69, 95\% CI: 1.51 - 1.89) (Table 4). After controlling for maternal age, BMI, parity, type 2 diabetes, GDM and excessive weight gain, multivariable analysis of factors associated with Apgar at 5 minutes $<7$ were unchanged (Table 4). Further multivariable analysis of factors associated with Apgar at 5 minutes $<7$ indicated that the increased risk of IGT, GDM and type 2 diabetes diagnosis is partially explained by gestational hypertension, high placental ratio, gestational age and LGA (Table 4, multivariable model 3).

\section{Discussion}

The results indicated that in London, Canada the prevalence of maternal glucose disorders increased by $65 \%$ for IGT, $52 \%$ for GDM and $206 \%$ for type 2 diabetes between 2000 and 2009. While maternal glucose disorders were shown to be associated with overweight and obesity, the temporal increase in maternal glucose disorders over the ten year period was not explained by similar increases in BMI. Examination of outcomes indicated that being diagnosed with IGT, GDM and type 2 diabetes did increase the risk of having an Apgar score $<7$ at 5 minutes.

To our knowledge, this is the first study to analytically examine the relationship between prevalence of maternal glucose disorders and obesity over time. Nine studies previously examined the changing prevalence in GDM during various time points between 1979 and 2005 [3-12]. One study found that the prevalence of GDM was stable between 1999-2005 in a Southern California population while the prevalence of type 2 diabetes increased [11]. The remaining studies demonstrated an increase in GDM that ranged from 12\% [5] to 127\% [4]. While each of these studies was able to examine the influence of ethnicity on the rising prevalence of GDM, most found that this increase was independent of ethnicity or only partially explained by ethnicity. None of the previous studies examining the time trend of maternal glucose disorders had access to pre-pregnancy BMI to determine if overweight/obesity played a role. As predicted by the literature, we found that elevated BMI was a major risk factor for developing GDM [22]. However, we also found that BMI $\geq 25 \mathrm{~kg} / \mathrm{m}^{2}$ did not increase

Table 1 Body mass index and metabolic disorders

\begin{tabular}{|c|c|c|c|c|c|c|}
\hline & $\begin{aligned}< & <18.5 \\
(\mathrm{~N} & =1618)\end{aligned}$ & $\begin{array}{c}18.5-24.9 \\
(N=15898)\end{array}$ & $\begin{array}{c}25.0-29.9 \\
(\mathrm{~N}=6272)\end{array}$ & $\begin{array}{l}30.0-34.9 \\
(\mathrm{~N}=2571)\end{array}$ & $\begin{array}{l}35.0-39.9 \\
(N=1067)\end{array}$ & $\begin{array}{c}>40.0 \\
(N=560)\end{array}$ \\
\hline Previous GDM & $9(0.6 \%)$ & $132(0.8 \%)$ & $129(2.1 \%)$ & 81 (3.2\%) & $58(5.4 \%)$ & $39(7.0 \%)$ \\
\hline Type 2 Diabetes & $5(0.2 \%)$ & $52(0.3 \%)$ & $48(0.8 \%)$ & $28(1.1 \%)$ & $23(2.2 \%)$ & $23(4.1 \%)$ \\
\hline IGT & $21(1.3 \%)$ & $110(0.7 \%)$ & 87 (1.4\%) & 37 (1.4\%) & $17(1.6 \%)$ & $11(2.0 \%)$ \\
\hline GDM & $5(0.3 \%)$ & $316(2.0 \%)$ & 299 (4.8\%) & 193 (7.5\%) & $111(10.4 \%)$ & 95 (17.0\%) \\
\hline
\end{tabular}

Values are number diagnosed (\%). GDM, gestational diabetes mellitus; IGT, impaired glucose tolerance. 
Table 2 Univariable and multivariable analysis of factors associated with impaired glucose tolerance (IGT), gestational diabetes mellitus (GDM) and type 2 diabetes

\begin{tabular}{|c|c|c|c|c|c|}
\hline & & Univariable & Multivariable & Multivariable + BMI & $\begin{array}{l}\text { Multivariable + BMI + } \\
\text { Excessive Weight Gain }\end{array}$ \\
\hline \multirow[t]{3}{*}{ Year } & IGT & $1.65(1.12-2.43)$ & $1.65(1.12-2.43)$ & $2.09(1.36-3.20)$ & $2.09(1.36-3.20)$ \\
\hline & GDM & $1.52(1.25-1.83)$ & $1.52(1.12-2.43)$ & $1.68(1.35-2.10)$ & $1.68(1.35-2.10)$ \\
\hline & Type 2 & $2.06(1.29-3.27)$ & $2.07(1.30-3.28)$ & $2.33(1.38-3.92)$ & $2.34(1.39-3.94)$ \\
\hline \multirow[t]{3}{*}{ Maternal Age ( $\geq 35$ vs. <35) } & IGT & $1.50(1.13-1.96)$ & $1.60(1.22-2.10)$ & $1.40(1.03-1.9)$ & $1.40(1.03-1.9)$ \\
\hline & GDM & $2.46(2.18-2.77)$ & $2.39(2.12-2.70)$ & $2.31(2.01-2.66)$ & $2.31(2.0-2.65)$ \\
\hline & Type 2 & $2.11(1.58-2.83)$ & $2.07(1.54-2.79)$ & $1.97(1.41-2.76)$ & $1.99(1.42-2.79)$ \\
\hline \multirow[t]{3}{*}{ Parity ( $\geq 1$ vs. 0 ) } & IGT & $0.82(0.66-1.03)$ & $0.77(0.61-0.96)$ & $0.75(0.58-0.96)$ & $0.75(0.58-0.96)$ \\
\hline & GDM & $1.31(1.17-1.46)$ & $1.13(1.01-1.27)$ & $0.95(0.83-1.08)$ & $0.94(0.83-1.08)$ \\
\hline & Type 2 & $1.23(0.94-1.61)$ & $1.10(0.84-1.44)$ & $0.91(0.67-1.23)$ & $0.93(0.69-1.26)$ \\
\hline \multirow[t]{3}{*}{ BMI $(25.0-29.9$ vs. $<25.0)$} & IGT & $2.22(1.69-2.94)$ & & $2.24(1.69-2.92)$ & $2.24(1.69-2.96)$ \\
\hline & GDM & $2.58(2.21-3.03)$ & & $2.52(2.15-2.96)$ & $2.52(2.15-2.96)$ \\
\hline & Type 2 & $2.54(1.67-3.61)$ & & $2.41(1.64-3.55)$ & $2.41(1.64-3.55)$ \\
\hline \multirow[t]{3}{*}{ BMI: ( $\geq 30.0$ vs. <25.0) } & IGT & $2.65(1.95-3.6)$ & & $2.68(1.97-3.65)$ & $2.68(1.97-3.65)$ \\
\hline & GDM & $5.50(4.74-6.39)$ & & $5.43(4.67-6.31)$ & $5.39(4.63-6.27)$ \\
\hline & Type 2 & $6.03(4.26-8.54)$ & & $5.96(4.21-8.44)$ & $6.11(4.30-8.67)$ \\
\hline \multirow[t]{3}{*}{ Excessive Weight Gain (> 20 kg) } & IGT & $1.06(0.75-1.48)$ & & & $1.00(0.70-1.42)$ \\
\hline & GDM & $0.77(0.64-0.92)$ & & & $0.91(0.74-1.11)$ \\
\hline & Type 2 & $1.16(0.79-1.71)$ & & & $1.36(0.90-2.05)$ \\
\hline
\end{tabular}

Multivariable analysis includes year, maternal age and parity.

Multivariable + BMI analysis includes year, maternal age, parity and BMI.

Predictive factors were entered in a blockwise fashion in order to allow for a careful examination of the relative contributions of each predictive factor to the relationship between year and MGDs. Year, maternal age and parity were entered in the first block, BMI in the second block and excessive weight gain in the third block.

significantly between 2000 and 2009 in our obstetrical population. These results are surprising as they are in contrast to Kim et al [17] who examined obesity rates in nine US states and found that the prevalence of maternal obesity (BMI $>29 \mathrm{~kg} / \mathrm{m}^{2}$ ) and overweight (BMI $26.0-29.0 \mathrm{~kg} / \mathrm{m}^{2}$ ) increased by $69.3 \%$ and $18.6 \%$ between 1993 and 2003, respectively. In the present study, after controlling for maternal age, parity and prepregnancy BMI, the impact of year was a $209 \%$ increase in IGT, a $168 \%$ increase in GDM and a $233 \%$ increase in pre-existing type 2 diabetes. These results suggest that there are other important variables affecting the prevalence of maternal glucose disorders. Postulated mechanisms include physical inactivity or excessive intake of dietary fat $[23,24]$. Further research is required.

The results of the univariable analyses in the present study found that the risk of low Apgar scores was related to diagnosis of IGT, GDM, T2 D, obesity,

Table 3 The impact of maternal glucose disorders on maternal and fetal pregnancy outcomes

\begin{tabular}{|c|c|c|c|c|}
\hline & IGT & GDM & T2D & Normal \\
\hline & $\begin{array}{c}\text { Percent or Mean } \\
\qquad \mathrm{N}=317\end{array}$ & $\begin{array}{l}\text { Percent or Mean } \\
\qquad \mathrm{N}=1342\end{array}$ & $\begin{array}{c}\text { Percent or Mean } \\
\quad N=224\end{array}$ & $\begin{array}{l}\text { Percent or Mean } \\
\qquad \mathrm{N}=34714\end{array}$ \\
\hline Gestational Age (weeks) & $38.7 \pm 1.8$ & $38.2 \pm 1.9$ & $37.1 \pm 2.4$ & $39.0 \pm 2.0$ \\
\hline Birth Weight (g) & $3462 \pm 568$ & $3442 \pm 637$ & $3533 \pm 806$ & $3415 \pm 577$ \\
\hline Placental Weight (g) & $699 \pm 149$ & $714 \pm 200$ & $736 \pm 206$ & $674 \pm 171$ \\
\hline Placental Ratio & $0.2095 \pm 0.0340$ & $0.2095 \pm 0.0411$ & $0.2132 \pm 0.0475$ & $0.1993 \pm 0.0421$ \\
\hline LGA & $18.6 \%$ & $21.8 \%$ & $43.8 \%$ & $11.2 \%$ \\
\hline SGA & $6.6 \%$ & $7.2 \%$ & $2.7 \%$ & $8.4 \%$ \\
\hline Apgar 5 Minutes <7 & $2.5 \%$ & $2.5 \%$ & $3.1 \%$ & $1.6 \%$ \\
\hline C/S Delivery & $31.2 \%$ & $35.8 \%$ & $57.1 \%$ & $20.2 \%$ \\
\hline gestational hypertension & $15.5 \%$ & $15.6 \%$ & $28.1 \%$ & $7.5 \%$ \\
\hline
\end{tabular}

Values are mean \pm SD or number diagnosed (\%). GDM, gestational diabetes mellitus; T2 D, type 2 diabetes; LGA, large for gestational age; SGA, small for gestational age; Apgar, appearance, grimace, pulse, activity, respiration; C/S, caesarean. 
Table 4 Univariable and multivariable analysis of factors associated with Apgar scores less than 7 at 5 minutes

\begin{tabular}{|c|c|c|c|c|}
\hline & Univariable & $\begin{array}{c}\text { Multivariable } \\
\text { Model } 1\end{array}$ & $\begin{array}{c}\text { Multivariable } \\
\text { Model } 2\end{array}$ & $\begin{array}{c}\text { Multivariable } \\
\text { Model } 3\end{array}$ \\
\hline Type 2 Diabetes & $2.99(2.17-4.12)$ & $2.41(1.66-3.48)$ & $2.40(1.66-3.48)$ & $1.29(0.85-1.95)$ \\
\hline Maternal Age ( $\geq 35$ vs. <35) & $1.01(1.00-1.02)$ & $1.02(1.01-1.03)$ & $1.02(1.01-1.03)$ & $1.02(1.01-1.03)$ \\
\hline BMI (25.0-29.9 vs. <25.0) & $1.22(1.11-1.35)$ & $1.22(1.10-1.35)$ & $1.22(1.10-1.35)$ & $1.25(1.12-1.41)$ \\
\hline BMI: ( $\geq 30.0$ vs. <25.0) & $1.54(1.38-1.71)$ & $1.53(1.36-1.71)$ & $1.53(1.37-1.71)$ & $1.43(1.25-1.63)$ \\
\hline Parity ( $\geq 1$ vs. 0) & $0.61(0.57-0.66)$ & $0.55(0.50-0.60)$ & $0.55(0.51-0.60)$ & $0.55(0.50-0.61)$ \\
\hline IGT & $1.87(1.36-2.56)$ & $1.81(1.30-2.53)$ & $1.81(1.30-2.53)$ & $1.49(1.03-2.15)$ \\
\hline GDM & $1.50(1.27-1.77)$ & $1.25(1.03-1.52)$ & $1.25(1.03-1.52)$ & $0.95(0.76-1.20)$ \\
\hline Excessive Weight Gain & $1.08(0.97-1.21)$ & & $1.03(0.92-1.16)$ & $1.10(0.85-1.95)$ \\
\hline Gestational Hypertension & $1.69(1.51-1.89)$ & & & $0.99(0.85-1.16)$ \\
\hline High Placental Ratio & $1.93(1.76-2.12)$ & & & $1.37(1.23-1.539)$ \\
\hline Gestational Age & $0.79(0.78-0.80)$ & & & $0.82(0.81-0.84)$ \\
\hline LGA & $1.44(1.30-1.59)$ & & & $1.55(1.35-1.77)$ \\
\hline
\end{tabular}

Model 1 includes maternal age, body mass index (BMI), and parity.

Model 2 includes Model 1 plus impaired glucose tolerance (IGT), gestational diabetes mellitus (GDM), type 2 diabetes and excessive weight gain.

Model 3 includes Model 2 plus gestational hypertension, placental ratio, gestational age and large for gestational age (LGA).

gestational hypertension and high placental ratio. However, after controlling for confounding factors, the low Apgar scores associated with IGT, GDM and T2 D were partially explained by concurrent diagnosis of gestational hypertension, having a high placental ratio, gestational age and delivering an LGA infant. It was further found that pre-pregnancy obesity was an independent risk factor for low Apgar scores. Therefore, it is important that clinicians consider maternal obesity alone as an independent risk factor for adverse pregnancy outcomes. Overall, it is important to note that associations with Apgar $<7$ were modest $(\mathrm{OR}<2.0)$ for all factors, even those with high statistical significance, indicating weak evidence of true associations.

There are three limitations to this paper that should be addressed in future investigations. First, the database does not identify the ethnicity of the women in the sample. According to available 1996 and 2006 Canadian Census [25,26], the ethnic distribution of London has changed modestly between those two years. Previous studies have demonstrated that ethnicity did have a small impact on prevalence of MDG, however, did not fully explain time trends in MDG [3-11]. Since we were not able to assess whether control for ethnicity might modify the estimated impact of other factors in our analyses, the influence of ethnicity on our findings cannot be completely ruled out.

The second limitation of the study was that the database did not indicate if all women in our cohort were screened for GDM. In Canada, it is recommended that all women be screened between 24-28 weeks gestation based on national guidelines by the Canadian Diabetes
Association [1,2]. However, the main goal of the present study was to examine the relationship between changing prevalence of maternal glucose disorders and obesity. Therefore, we feel that this is a significant step forward in our understanding of why maternal glucose disorders are increasing in the obstetrical population.

Finally, height and weight data contributing to the calculation came from variable sources, including selfreport, therefore misreporting will have influenced the accuracy of BMI. We speculate it may have produced an underestimate in BMI. However, this underestimate is likely to be non-differential in regards to year, and therefore this would not explain the negative finding.

\section{Conclusion}

This is the first study to investigate the relationship between increasing prevalence of maternal glucose disorders and obesity. Contrary to our hypothesis, the results of the present study indicated that the rising prevalence of maternal glucose disorders is not related to increasing BMI.

\section{Acknowledgements}

MH Davenport was supported by a doctoral research scholarship from the Canadian Institute for Health Research and an Ontario Graduate Scholarship. The authors wish to acknowledge Dr. Rob Gratton and Dr. Henry Roukema for allowing access to the St. Joseph's Health Care Perinatal Database. The authors wish to acknowledge Larry Stitt of the University of Western Ontario Biostatistical Support Unit for his aid in the statistical analyses of this project.

\section{Author details}

${ }^{1}$ R. Samuel McLaughlin Foundation Exercise and Pregnancy Lab, School of Kinesiology, The University of Western Ontario, London, Ontario, N6A 3K7, Canada. ${ }^{2}$ Department of Epidemiology and Biostatistics, The University of 
Western Ontario, London, Ontario, N6A 3K7, Canada. ${ }^{3}$ Department of Obstetrics and Gynecology, The University of Western Ontario, London, Ontario, N6A 3K7, Canada. ${ }^{4}$ Department of Paediatrics, The University of Western Ontario, London, Ontario, N6A 3K7, Canada. ${ }^{5}$ Childrens Health Research Institute, The University of Western Ontario, London, Ontario, N6A 3K7, Canada. ${ }^{6}$ Department of Anatomy and Cell Biology, The University of Western Ontario, London, Ontario, N6A 3K7, Canada.

\section{Authors' contributions}

MHD contributed to the design, analysis and interpretation of the data and the drafting of the manuscript. MKC and MFM contributed to the design and interpretation of the data and reviewed the manuscript. All authors have read and approved the final manuscript.

\section{Competing interests}

The authors declare that they have no competing interests.

Received: 22 September 2010 Accepted: 24 December 2010 Published: 24 December 2010

\section{References}

1. Canadian Diabetes Association Clinical Practice Guidelines Expert Committee: Gestational diabetes mellitus. Canadian Medical Association Journal 2003, 169:S99-S105.

2. Canadian Diabetes Association: Canadian Diabetes Association 2008 Clinical Practicie Guidelines for the Prevention and Management of Diabetes in Canada. Canadian Journal of Diabetes 2008, 32:S0-S201.

3. Ferrara $A$, Kahn HS, Quesenberry $C P$, Riley $C$, Hedderson MM: An increase in the incidence of gestational diabetes mellitus: Northern California, 1991-2000. Obstet Gynecol 2004, 103:526-533.

4. Beischer NA, Oats JN, Henry OA, Sheedy MT, Walstab JE: Incidence and severity of gestational diabetes mellitus according to country of birth in women living in Australia. Diabetes 1991, 40(Suppl 2):35-38.

5. Ishak M, Petocz P: Gestational diabetes among Aboriginal Australians: prevalence, time trend, and comparisons with non-Aboriginal Australians. Ethn Dis 2003, 13:55-60.

6. Dabelea D, Snell-Bergeon JK, Hartsfield CL, Bischoff KJ, Hamman RF, McDuffie RS: Increasing prevalence of gestational diabetes mellitus (GDM) over time and by birth cohort: Kaiser Permanente of Colorado GDM Screening Program. Diabetes Care 2005, 28:579-584.

7. Moum KR, Holzman GS, Harwell TS, Parsons SL, Adams SD, Oser CS, Spence MR, Helgerson SD, Gohdes D: Increasing rate of diabetes in pregnancy among American Indian and white mothers in Montana and North Dakota, 1989-2000. Matern Child Health J 2004, 8:71-76.

8. Thorpe LE, Berger D, Ellis JA, Bettegowda VR, Brown G, Matte T, Bassett M, Frieden TR: Trends and racial/ethnic disparities in gestational diabetes among pregnant women in New York City, 1990-2001. Am J Public Health 2005, 95:1536-1539.

9. Anna V, van der Ploeg HP, Cheung NW, Huxley RR, Bauman AE: Sociodemographic correlates of the increasing trend in prevalence of gestational diabetes mellitus in a large population of women between 1995 and 2005. Diabetes Care 2008, 31:2288-2293.

10. Shand AW, Bell JC, McElduff A, Morris J, Roberts CL: Outcomes of pregnancies in women with pre-gestational diabetes mellitus and gestational diabetes mellitus; a population-based study in New South Wales, Australia, 1998-2002. Diabet Med 2008, 25:708-715.

11. Lawrence JM, Contreras R, Chen W, Sacks DA: Trends in the prevalence of preexisting diabetes and gestational diabetes mellitus among a racially/ ethnically diverse population of pregnant women, 1999-2005. Diabetes Care 2008, 31:899-904.

12. Ferrara A: Increasing prevalence of gestational diabetes mellitus: a public health perspective. Diabetes Care 2007, 30(Suppl 2):S141-S146.

13. Jovanovic L, Pettitt DJ: Gestational diabetes mellitus. JAMA 2001, 286:2516-2518.

14. Dempsey JC, Butler CL, Sorensen TK, Lee IM, Thompson ML, Miller RS, Frederick IO, Williams MA: A case-control study of maternal recreational physical activity and risk of gestational diabetes mellitus. Diabetes Res Clin Pract 2004, 66:203-215.

15. Dempsey JC, Sorensen TK, Williams MA, Lee IM, Miller RS, Dashow EE, Luthy DA: Prospective study of gestational diabetes mellitus risk in relation to maternal recreational physical activity before and during pregnancy. Am J Epidemiol 2004, 159:663-670.

16. Flegal KM, Carroll MD, Ogden CL, Johnson CL: Prevalence and trends in obesity among US adults, 1999-2000. JAMA 2002, 288:1723-1727.

17. Kim SY, Dietz PM, England L, Morrow B, Callaghan WM: Trends in prepregnancy obesity in nine states, 1993-2003. Obesity (Silver Spring) 2007, 15:986-993.

18. Doherty DA, Magann EF, Francis J, Morrison JC, Newnham JP: Prepregnancy body mass index and pregnancy outcomes. Int I Gynaecol Obstet 2006, 95:242-247.

19. Abenhaim HA, Kinch RA, Morin L, Benjamin A, Usher R: Effect of prepregnancy body mass index categories on obstetrical and neonatal outcomes. Arch Gynecol Obstet 2007, 275:39-43.

20. Kramer MS, Platt RW, Wen SW, Joseph KS, Allen A, Abrahamowicz M, Blondel B, Breart G: A new and improved population-based Canadian reference for birth weight for gestational age. Pediatrics 2001, 108:E35.

21. ACOG Committee Opinion. Number 333, May 2006 (replaces No. 174, July 1996): The Apgar score. Obstet Gynecol 2006, 107:1209-1212.

22. Solomon CG, Willett WC, Carey VJ, Rich-Edwards J, Hunter DJ, Colditz GA, Stampfer MJ, Speizer FE, Spiegelman D, Manson JE: A prospective study of pregravid determinants of gestational diabetes mellitus. JAMA 1997, 278:1078-1083.

23. Oken E, Ning Y, Rifas-Shiman SL, Radesky JS, Rich-Edwards JW, Gillman MW: Associations of physical activity and inactivity before and during pregnancy with glucose tolerance. Obstet Gynecol 2006, 108:1200-1207.

24. Radesky JS, Oken E, Rifas-Shiman SL, Kleinman KP, Rich-Edwards JW, Gillman MW: Diet during early pregnancy and development of gestational diabetes. Paediatr Perinat Epidemiol 2008, 22:47-59.

25. Canadian Census - 1996 Community Profile. [http://www12.statcan.ca/ english/Profil/Details/details1.cfm?SEARCH=BEGINS\&ID=7689\&PSGC= $35 \& S G C=3539036 \&$ DataType $=1 \&$ LANG $=$ E\&Province $=35 \&$ PlaceName=london\&CMA=555\&CSDNAME=London\&A=\&TypeNameE=City]

26. Canadian Census - 2006 Community Profile. [http://www12.statcan.ca/ census-recensement/2006/dp-pd/prof/92-591/details/Page.cfm? Lang $=E \& G e 01=C S D \& C o d e 1=3539036 \& G e 02=P R \& C o d e 2=35 \&$ Data $=$ Count\&SearchText=london\&SearchType $=$ Begins\&SearchPR $=$ 35\&B1=All\&Custom $=]$.

\section{Pre-publication history}

The pre-publication history for this paper can be accessed here: http://www.biomedcentral.com/1471-2393/10/85/prepub

\section{doi:10.1186/1471-2393-10-85}

Cite this article as: Davenport et al.: Increased incidence of glucose disorders during pregnancy is not explained by pre-pregnancy obesity in London, Canada. BMC Pregnancy and Childbirth 2010 10:85.

\section{Submit your next manuscript to BioMed Central and take full advantage of:}

- Convenient online submission

- Thorough peer review

- No space constraints or color figure charges

- Immediate publication on acceptance

- Inclusion in PubMed, CAS, Scopus and Google Scholar

- Research which is freely available for redistribution

Submit your manuscript at www.biomedcentral.com/submit
C Biomed Central 